\title{
Radiation doses assessment for workers on radiation measuring devices response check in RNSD laboratories
}

\author{
Abbas N. Mohammed, Zaki A. Mansoor, Zainab M. Jbara \\ Radiation \& Nuclear Safety Directorate, Ministry of Science \& Technology \\ E-mail: abbasneamah@gmail.com
}

\begin{abstract}
Radiation measuring devices need to periodic calibration process to examine their sensitivity and the extent of the response. This study is used to evaluate the radiation doses of the workers in the laboratories of the Directorate of Safety as a result of the use of point sources in calibrating of the devices in two ways, the first is the direct measurement by the FAG device and the others using RESRAD and RAD PRO programs. The total doses values using FAG were $(2.57 \mu \mathrm{Sv} / \mathrm{y}, 102.3 \mu \mathrm{Sv} / \mathrm{y}$ and $20.75 \mu \mathrm{Sv} / \mathrm{y}$ for TLD laboratory, Gamma spectroscopy analyses (GSA) laboratory and equipment store respectively, and the total doses that calculated using RESRAD and RAD PRO were $1.518 \mu \mathrm{Sv} / \mathrm{y}, 76.65 \mu \mathrm{Sv} / \mathrm{y}$ and $21.2 \mu \mathrm{Sv} / \mathrm{y}$ for the above laboratories. the dose rate is very low compare with the national, international dose rate limits $(20 \mathrm{mSv} / \mathrm{y})$.
\end{abstract}

Key words

Radioactive sources, calibration, radiation doses.

Article info.

Received: Aug. 2018

Accepted: Oct. 2018

Published: Mar. 2019

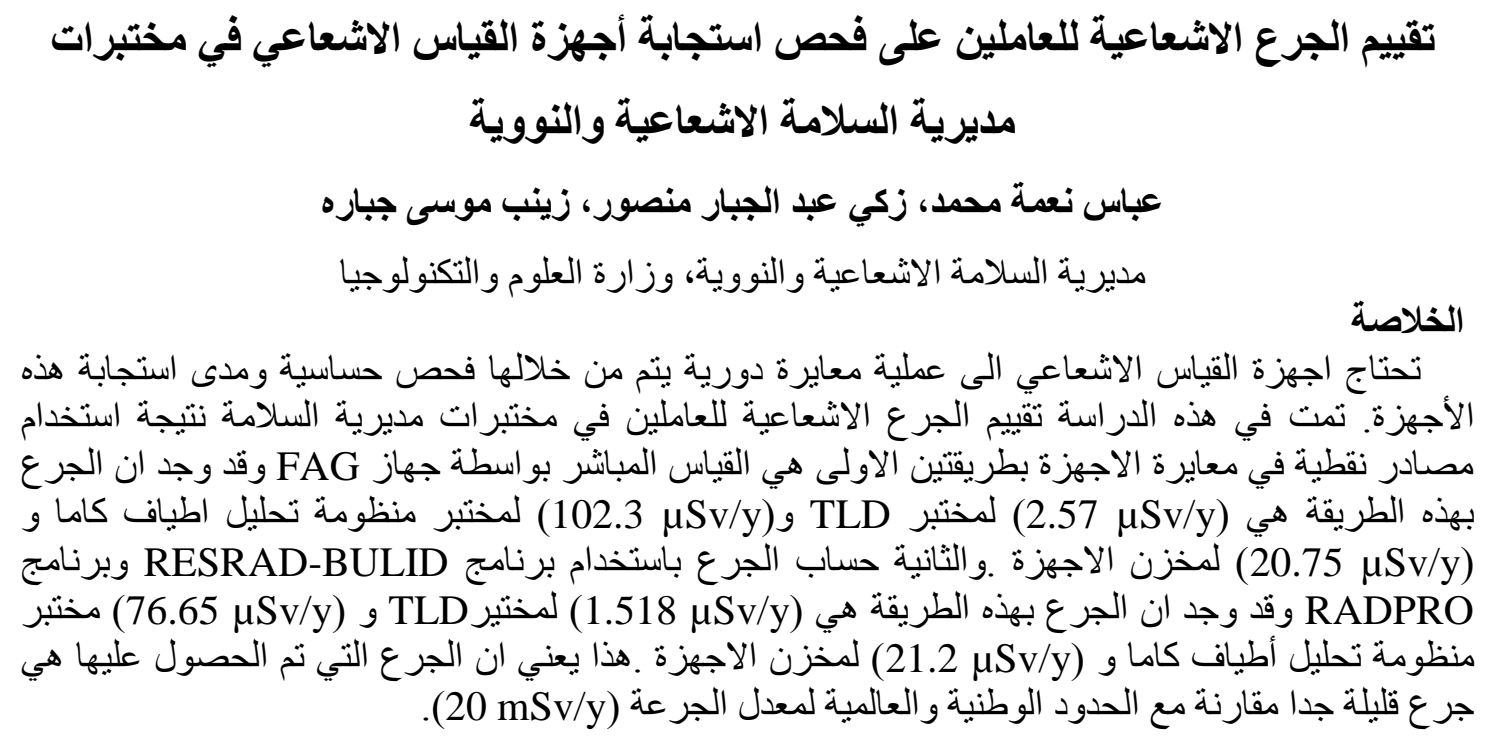

\section{Introduction}

Everyone in our world is exposed to the ionizing radiations which are emitted by radioactive materials in the environment where we are living. The sources of these radiations are natural as well as man-made. The natural sources of radiation are cosmic rays and natural radioactivity present in the soil and rocks [1], the cosmic ray particles incident on the earth's atmosphere consist of a mixture of electrons, protons, $\alpha$-particle, and a just detectable amount of heavier nuclei.

Radioactive sources are used throughout the world in medicine, industry, agriculture, research and education; they are also used in some military applications. Many of these sources are made as sealed sources 
with the radioactive materials firmly contained or bound within a suitable capsule or housing. The risks posed by these sources vary widely, depending on such factors as the radionuclides used, the physical and chemical form and the activity [2]. Sealed and unsealed radioactive sources are used for a variety of purposes and they incorporate a wide range of radionuclides and amounts of radioactive material. High activity sources, if not managed safely and securely, can cause severe deterministic effects to individuals in a short period of time [3, 4], whereas low activity sources are unlikely to cause exposures with harmful consequences. A radioactive source is considered dangerous if its misuse could be life threatening or could cause a permanent injury that would reduce the quality of life of the person exposed. Possible permanent injuries include burns requiring surgery $[5,6]$. Temporary injuries such as reddening and irritation of the skin or temporary changes to the composition of the blood are not considered dangerous. The extent of any such injuries will depend on many factors, including: the activity of the radioactive source; how close a person is to the source and for how long; whether the source is shielded; and whether or not its radioactive material has been dispersed, thus leading to contamination of the skin or inhalation or ingestion[7,8]. For the purposes of categorization, any possible harm from delayed effects of radiation such as radiation induced cancer developing later in life in any persons who are exposed is treated as secondary consideration to the paramount need to protect against the dangerous consequences described above [9]. This study aims to assess the rate dose and risk that received by workers in Radiation and Nuclear Safety Directorate (RNSD) in AL-Tuwitha nuclear site laboratories during the calibration of devises by using radioactive sources.

\section{Materials and methods}

The equipment and codes used are listed below:

1. The (FAG) model (FH40F2) RADIAMETER was used, it works within the range of $(0.01 \mu \mathrm{Sv} / \mathrm{h}$ $10 \mathrm{mSv} / \mathrm{h}$ ) to measure the exposure doses rate for the workers showing in Fig. 1 [10].

2. RESRAD-Build Computer Code Version 3.5 (2009). This computerized tool is prepared by Argonne National Laboratory. The RESRAD is a computer model designed to estimate radiation doses and risks from RESidual RADioactive materials [11]. 3. RAD PRO code used to calculate the activity of sources and performs many nuclear calculations that are useful to the health physicist, radiological researcher, radio chemist, radiation safety officer, health physics technician (HP) and other professionals in radiation physics and radiological engineering. 


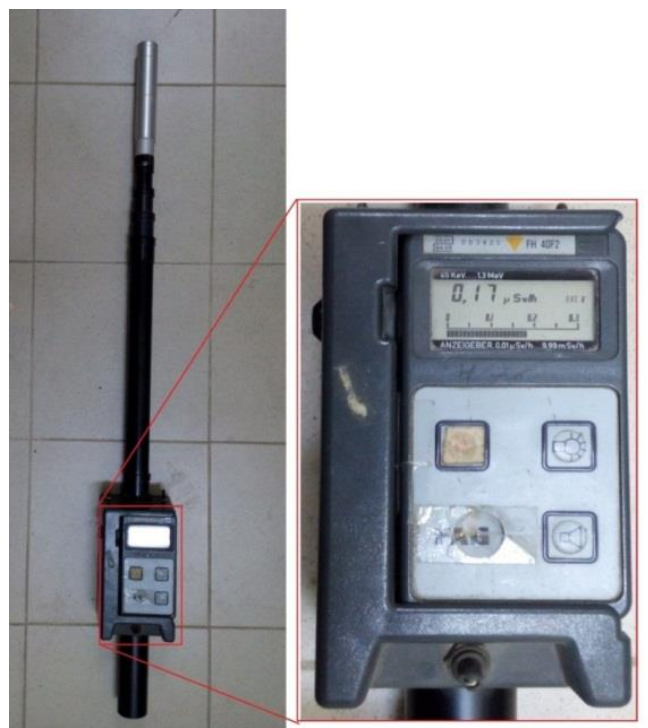

Fig. 1: FAG device.

\section{Results and discussion}

There are two methods are used to calculate the exposure dose that received by the worker:

Direct measurement using FAG portable device; Table 1 shows the data obtained and using the scenario which be taken to calculate the duration of exposure during the calibration method using the portable device type (FAG), the annual dose was found.

Calculation the doses using RESRAD Build Computer code, calculation the current radiation activity using RAD PRO code, and conservatively assumed for the worst case scenario that.

Table 1: The data taken by FAG portable device.

\begin{tabular}{|c|c|c|c|c|c|c|}
\hline No. & $\begin{array}{c}\text { Radioavtiv } \\
\text { e sources }\end{array}$ & Source Location & $\begin{array}{c}\text { Radiation } \\
\text { Activity } \\
\mathrm{MBq}\end{array}$ & $\begin{array}{c}\text { Production } \\
\text { date }\end{array}$ & Serial NO. & $\begin{array}{c}\text { Dose rate } \\
\mu \mathrm{Sv} / \mathrm{h}\end{array}$ \\
\hline 1 & Sr-90 & TLD Laboratory & 37 & $11-1985$ & $1456 \mathrm{BC}$ & $2.15^{*}$ \\
\hline 2 & Cs-137 & Store & 0.037 & $12-2003$ & 2608 & $4.21^{* *}$ \\
\hline 3 & K-40 & GSA Laboratory & $5.4 \times 10^{-5}$ & & & 2.5 \\
\hline 4 & Cs-137 & GSA Laboratory & $2.3 \times 10^{-3}$ & $1-2003$ & $67 \mathrm{E} 01$ & 0.25 \\
\hline 5 & Co-60 & GSA Laboratory & $4.94 \times 10^{-5}$ & & 7224 & 3.8 \\
\hline
\end{tabular}

* With shielding

** Without shielding

\section{TLD laboratory}

The personal dosimetry that means of thermo luminescence dosimeters model TOLEDO 654 TLD READER England, these devices typically use a single ${ }^{90} \mathrm{Sr}$ source for calibration method[6].

In this laboratory the calibration method carried out monthly with assuming the worker who calibrates the TLDs puts the discs and adjust the device before operating for 5 minutes at distance $30 \mathrm{~cm}$ and then operate the device and get out of the room so therefor we assume the worker stays for 30 seconds during operation. Therefore, the duration of stay with shielding 60 minutes per year at distance $15 \mathrm{~cm}$ and duration of stay 6 minutes per year without shielding, therefore the annual doses are $2.15 \mu \mathrm{Sv} / \mathrm{y}$ with shielding and 
$0.421 \mu \mathrm{Sv} / \mathrm{y}$ without shielding .The total dose is $2.57 \mu \mathrm{Sv} / \mathrm{y}$.

Using RAD PRO Calculator code to find current radioactivity from radioactive sources Generated date and radioactivity as shown in Table1 and Fig.2.

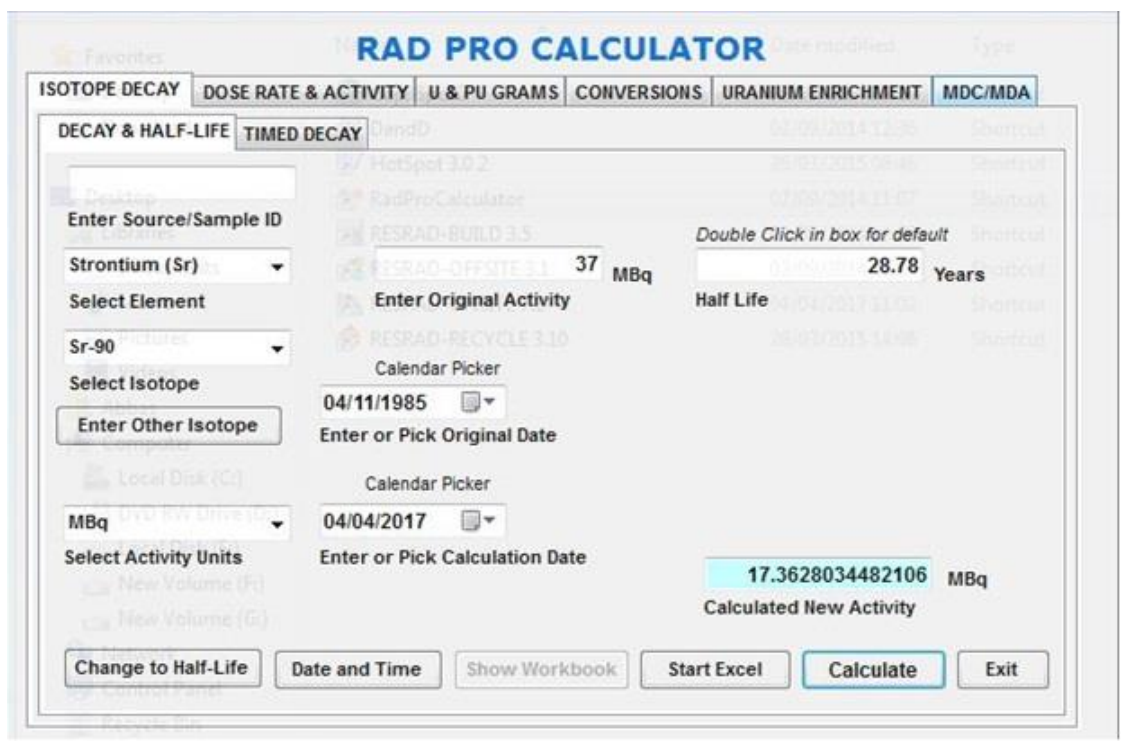

Fig.2: Calculation of current activity for Sr-90.

\section{RESRAD-BUILD}

Calculates doses to persons inside structures from radioactive materials on or in the walls, ceiling, or floors. RESRAD code provides individual exposure pathways (external, inhalation, deposition, ingestion, immersion and radon) doses

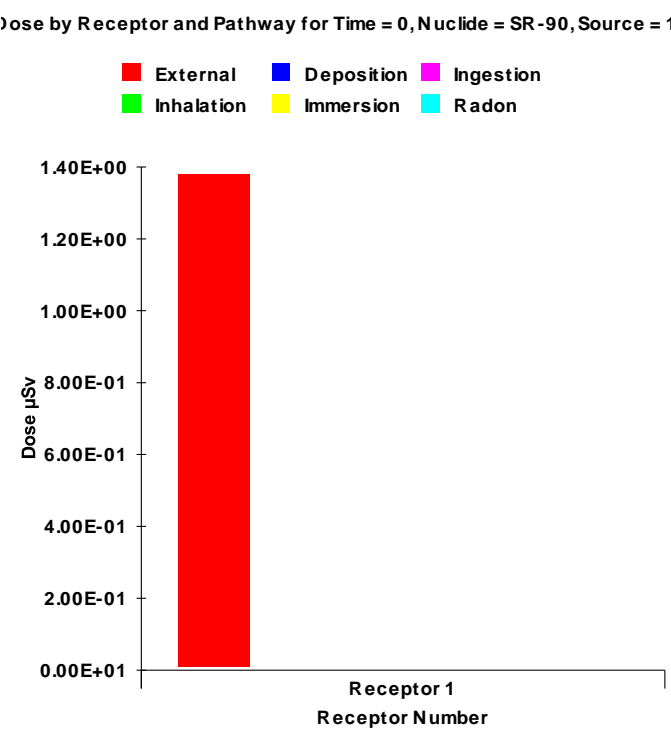

(a) contribution to the total dose. The dose without shielding $(1.38 \mu \mathrm{Sv} / \mathrm{y})$ and the dose with shielding $0.138 \mu \mathrm{Sv} / \mathrm{y}$ and the total individual pathway dose was estimated to be $(1.518 \mu \mathrm{Sv} / \mathrm{y})$ from external pathway only as shown in Fig.3 ( $a$ and $b$ ).

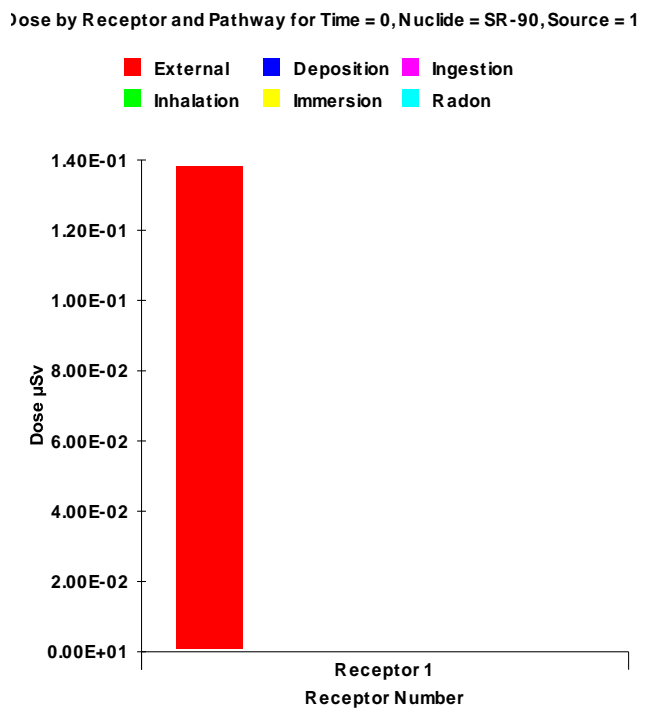

Fig.3: a- Dose without shielding, b-Dose with shielding. 


\section{Equipment store}

To estimate the dose received for the worker in the equipment store, using (FAG) device during the delivery of the equipment to examine the device on the source point (Cs-137) and worst case scenario, assume the duration of survival near the source to inspect the device is approximately 2 minutes so the exposure time of this worker 8.33 hour per year will stand at $3 \mathrm{~cm}$, the total dose is $20.75 \mu \mathrm{Sv} / \mathrm{y}$.

And the total dose that obtained using RESRAD-BUILD is $21.2 \mu \mathrm{Sv} / \mathrm{y}$, as shown in Fig.4.

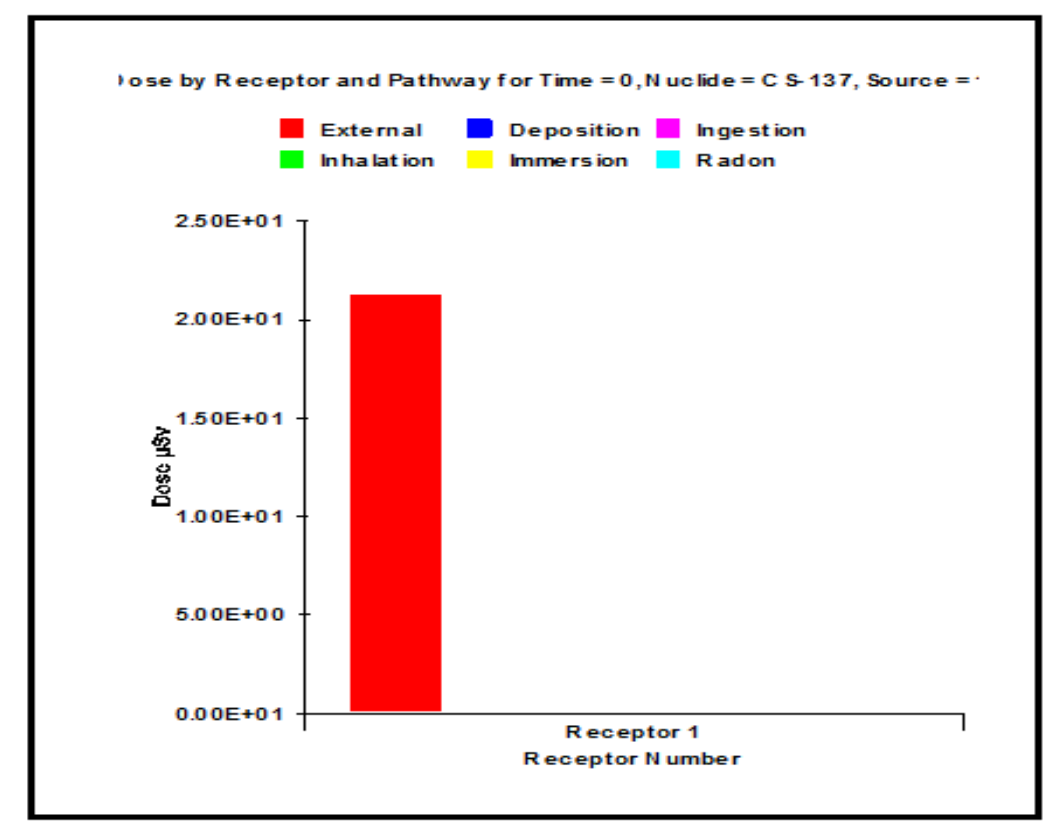

Fig.4: The total dose in equipment store.

Gamma Spectroscopy Analyses (GSA) laboratory

The scenario to calculate exposure period is the worker on calibration the germanium system daily and using three sources (K-40, Cs-137and Co-60) together for calibrating and the maximum duration of transferring the sources from it place to the system place and return to its place will be 5 minutes and the worse case will assume that the same person doing the work daily for all year. The maximum exposure period will be $20.8 \mathrm{~h} / \mathrm{y}$ and the total dose rate which measured using (FAG) device was $(4.92 \mu \mathrm{Sv} / \mathrm{h})$ therefore the annual dose will be 102.3 $\mu \mathrm{Sv} / \mathrm{y}$.
The RESRAD-BULID need the source activity to calculate the doses and two sources in germanium system laboratory do not contain the activity. The activity was calculated by RAD PRO program to be used in the RESRAD program. The activity of the Cs-137 source was calculated at the measure time based on the production date as shown in Fig. 5. The results of doses that obtained using RESRADBUILD are (47.6, 24.6 and 4.45) $\mu \mathrm{Sv} / \mathrm{y}$ for Co-60, Cs-137and K-40 sources respectively as shown in Fig.6, and the total dose is $76.65 \mu \mathrm{Sv} / \mathrm{y}$ as shown in Fig.7. 


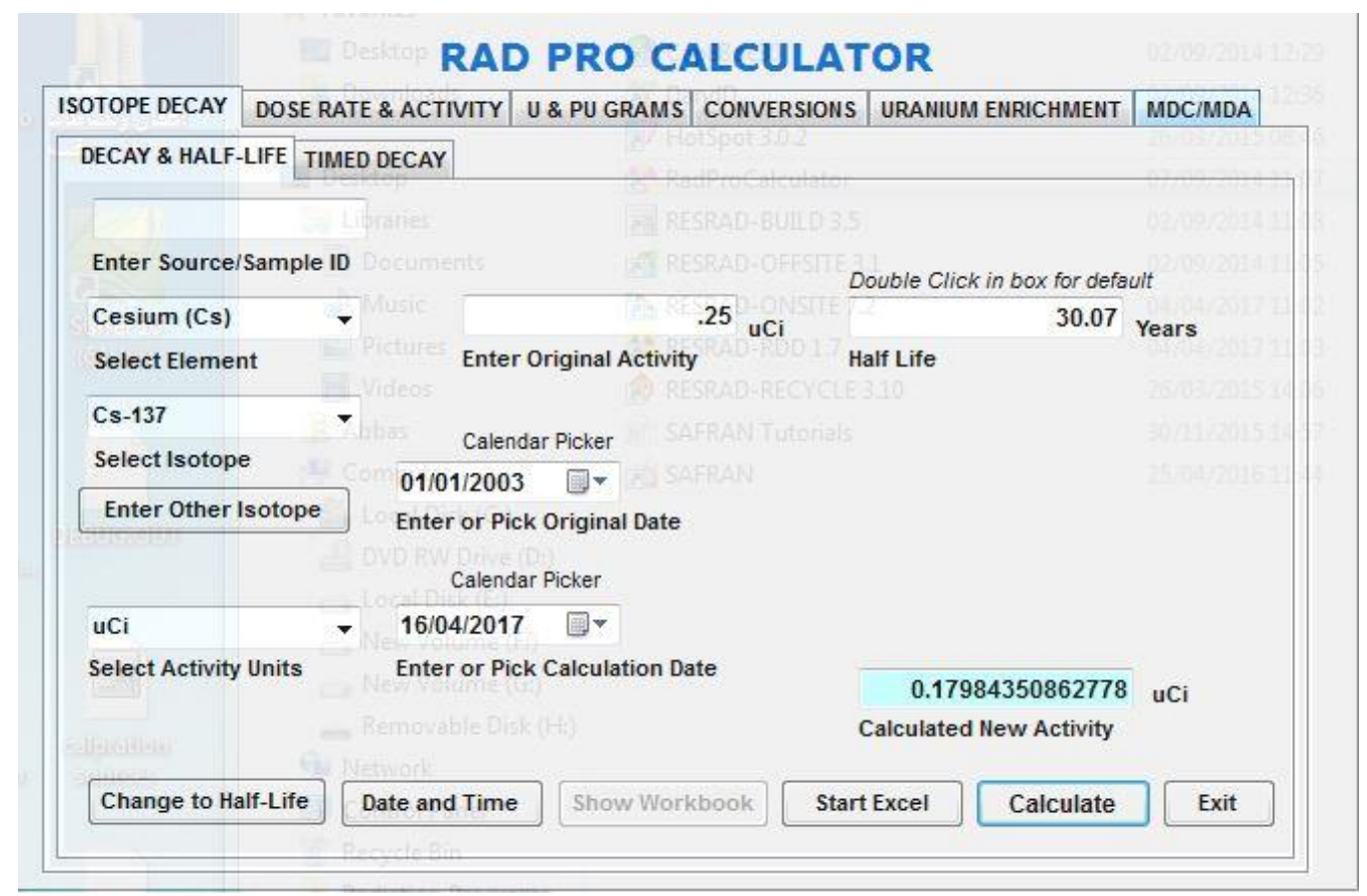

Fig.5: Calculation of current activity for CS-137.

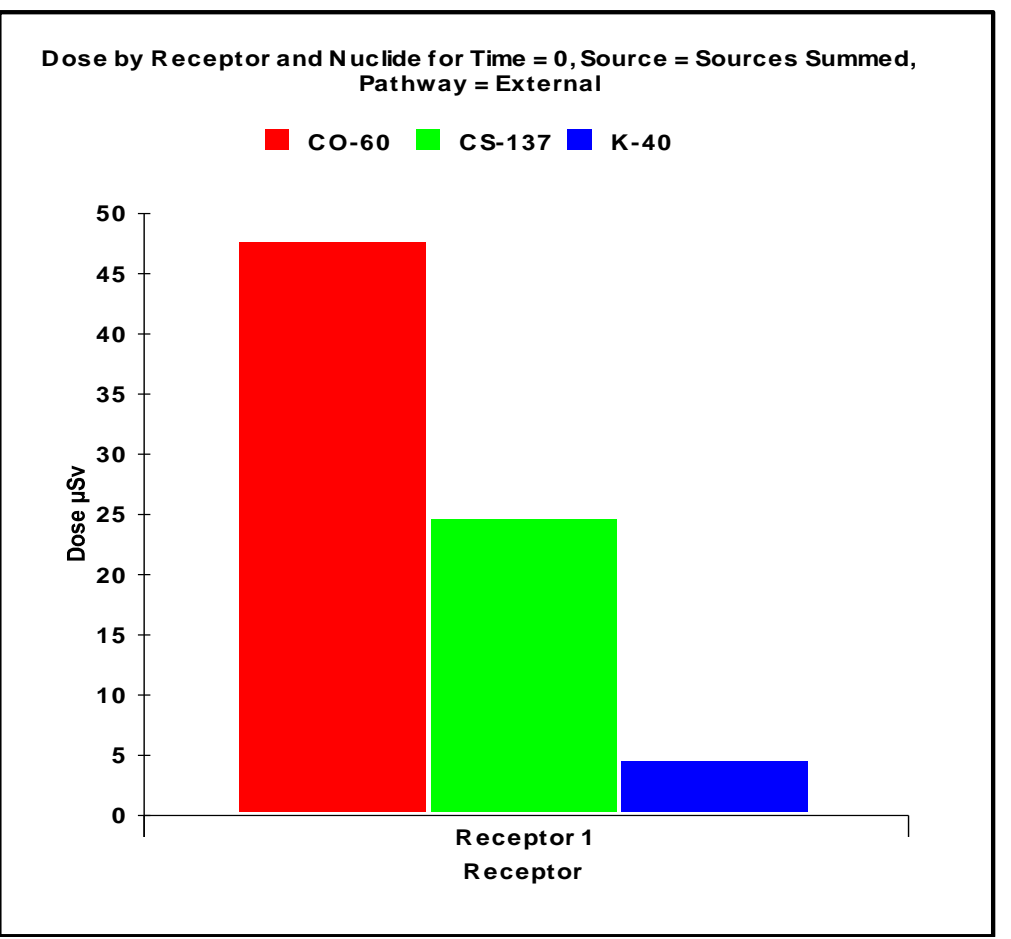

Fig.6: The doses from three sources in germanium system laboratory. 


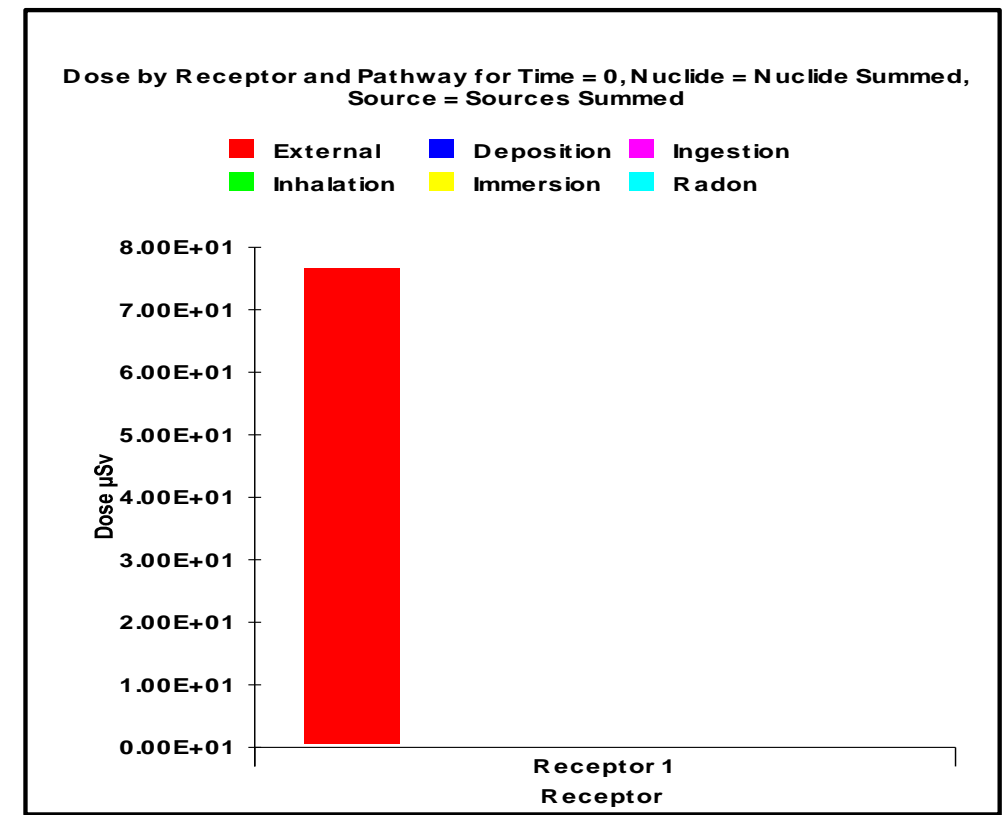

Fig.7: The total dose in germanium system laboratory.

\section{Conclusions}

The results show that the value of exposure for the workers in laboratories in this study as a result of the calibration process of the systems as well as the workers in the store of radiological equipment when the test of the device pre-delivery to the radioactive source and according to the mentioned scenario shows the following:

1- In the TLD laboratory, the annual dose measured using the FAG portable device was found to be $2.57 \mu \mathrm{Sv} / \mathrm{y}$ and using the RESRAD BUILD program is $1.52 \mu \mathrm{Sv} / \mathrm{y}$.

2- In the radiological equipment store, it was found that the annual dose measured using the FAG device is $20.75 \mu \mathrm{Sv} / \mathrm{y}$ and using the RESRAD BUILD program is $21.2 \mu \mathrm{Sv} / \mathrm{y}$.

3- In Germanium System Laboratory the annual dose measured using the FAG device is $102.3 \mu \mathrm{Sv} / \mathrm{y}$ and using the RESRAD BUILD program is $76.6 \mu \mathrm{Sv} / \mathrm{y}$.

There are very small differences between the readings of the portable device and the result of RESRAD BUILD program. This is normal because the program uses equations and inputs to calculate the annual doses.

\section{References}

[1] IAEA (International Atomic Energy Agency), Calibration of Radiation Protection Monitoring Instruments. Safety Reports Series No. 16, Vienna, 2000.

[2] Nada Fathil Tawfiq, HL Mansour, MS Karim, International Journal of Recent Research and Review, 8, 1 (2015) 1-7.

[3] UNSCEAR (United Nations Scientific Committee on the Effects of Atomic Radiation), "Sources and Effects of Ionizing Radiation", UNSCEAR 2000 Report Vol.1 to the General Assembly, with scientific annexes, United Nations Sales Publication, United Nations, New York, 2000.

[4] G. F. Knoll, "Radiation Detection and Measurement (3rd edition)", USA: John Wiley \& Sons Inc, 2000.

[5] IAEA (International Atomic Energy Agency), "characterization of radioactive waste forms and packages" T.R. series No. 383, IAEA, Vienna, 1997. 
[6] R.D. Senthilkumar, R. Narayanaswamy, Journal of Radiation Research and Applied Sciences, 9 (2016) 449-456.

[7] NCRP (National Council on Radiation Protection and Measurements), “A Handbook of Radioactivity Measurements Procedures (2nd edition)", NCRP Report No.58. NCRP, Maryland, 1985. [8] Canadian Nuclear Safety Commission (CNSC), "Introduction to Dosimetry", ISBN 978-1-100-19735-7, 2011.
[9] IAEA (International Atomic Energy Agency), Radiation Oncology Physics: A Handbook for Teachers And Students, IAEA, Vienna, 2005.

[10] FAG Kugelfischer Georg, Operating Manual for the Fag FH 40 F1-F6 RADIAMETER, 1986.

[11] C. Yu, D.J. LePoire, J.-J. Cheng, User's Manual for RESRAD-BUILD Version 3, Argonne National Laboratory, 9700 South Cass Avenue, Argonne, Illinois 60439, 2003. 